\title{
LIVING WITH URBAN FLOODS IN METRO MANILA: A GENDER APPROACH TO MOBILITIES, WORK AND CLIMATIC EVENTS
}

\begin{abstract}
With this paper, I demonstrate the importance of a gendered approach to work-related mobilities, in understanding the linkages between mobilities and urban flooding. Drawing on a qualitative study conducted in the Malate district in Metro Manila, I focus on work-related mobilities of low-income communities, particularly on the impact of floods on urban mobilities. Rather than considering floods as disasters, I conceptualise floods as part of everyday urban life, and demonstrate how climatic conditions traverse the dynamics of home-work linkages, localities and employment in the Urban South. I argue that bridging mobility and climatic conditions from a gender perspective brings forth how the conflicting narratives of confinement and independence are implicated in the everyday lives of the women living in low-income settlements. This eventually challenges current policy representations on the societal impacts of adverse weather and economic conditions on vulnerable communities.
\end{abstract}

Keywords: urban mobility; gender; floods; work; Manila 


\section{Introduction}

'It is women that are most affected by flooding... but flooding disrupts their [women's] work, not their access to work!'

An urban planner in Malate, September 2016

This short quote refers to women informal settlers in Metro Manila. It reveals the assumption that women living in informal settlements are immobile workers and that their work is mostly homebound. Indeed, women's disadvantages in connectivity, accessibility and access to livelihoods in urban South economies are explained by a variety of factors, such as women's restricted use of space and their taking on secondary roles in family businesses, therefore being relatively immobile (Chant, 2013; Chant and Mcllwaine, 2016). Such holistic perspectives into gender and urban poverty issues provide informative, all-encompassing descriptions of gendered economic disadvantages in the Global South, and are most welcome given the diversity and complexity of the matter. However, these broad framings classify climate-related events and risks, such as flooding, as contextual characteristics that affect these women. A lack of exploration into the lived experiences of floods in the context of urban poverty limits the understanding of what it really means to live with the threat of flood, for those already living in economically and physically inadequate conditions. In this paper, I am particularly concerned with how the nexus of climatic events and mobility is implicated in low-income communities' everyday urban spaces (i.e. work/home) with a specific focus on gender issues.

Many development scholars have provided evidence for differences between the perceptions and experiences (in relation to floods), preparedness, coping and adaptation strategies of women and men (Sultana, 2010; Bob and Babugura, 2014). Various forms of social axes, other than gender change power relations, are seen as rendering women more vulnerable to floods (Ajibade, McBean and Bezner-Kerr, 2013; Azad, Hossain and Nasreen, 2013; Bob and Babugura, 2014; Mason and Agan, 2015; Perez et al., 2015; Rufat et al., 2015). Specific work-related challenges that arise from floods are also found to be varied; from physical stress when driving to work, to loss of the goods that women derive income from (Ajibade, McBean and Bezner-Kerr, 2013).

In investigating the gender aspects of climate change, floods are also seen as disasters, onetime events only, as clearly evidenced in some articles comparing normal times and disaster/post-disaster conditions (Sultana, 2010; Ajibade, McBean and Bezner-Kerr, 2013; Ingham, Islam and Hicks, 2019). This particular conceptualisation underestimates the fact that, in many flood-prone areas, these climatic events have almost become part of everyday life in different ways, and the normalisation of these events by the residents has overarching implications for gender equality (Eastin, 2018). Moreover, most research on the (gendered) implications of floods has focused on rural contexts (Azad, Hossain and Nasreen, 2013; 
Akerkar, Joshi and Fordham, 2016), whilst the challenges that floods present to women in urban contexts are particularly significant for mobility. Given the high rates of urbanisation, and the increased vulnerability of low-income communities living in urban areas, more insight is needed into how floods intersect with everyday mobilities.

A gender lens on mobilities and work can help unpack the adverse societal impacts of climate-related risks, such as floods, on vulnerable communities, with a focus on the lived experiences of the everyday risk of flooding. It complicates the wider context by allowing us to identify mobility-related challenges, the wider meanings of mobilities embedded in different localities and the relationalities between different spaces of work-home negotiations in the face of floods. It is important to delineate such context-specific dynamics when studying non-Western contexts. For instance, the 'gendering' of the division of labour in the household, and of access to resources, explains how mobility constraints may restrict lowincome women's access to economic opportunities in the Global South, but this literature shows considerable differences between different political, economic, social and cultural contexts (Uteng, 2011; Akyelken, 2013; Levy, 2013; Elias, Benjamin and Shiftan, 2017).

Through this conceptual lens, I will explore how gender differences in work-related mobilities manifest themselves when one considers flooding in a complex web of interconnectedness between households, workplaces and people. How does gender play a role in everyday mobilities in a flood-prone context? Are the disruptions caused by flooding implicated in everyday life in relation to reaching economic opportunities? I seek to answer these questions through a case study of a low-income settlement in the city of Manila, a Southeast Asian city characterised by high levels of economic inequality, where the causes of vulnerability to flooding are significantly pronounced. Drawing on the gendered mobilities and work literature, I first start by exploring how the lived experiences of women in getting to work co-evolve with the wider environmental, physical and economic risks to which the informal settlements are exposed. I then provide narratives of how a relational approach to work-home links, localities and everyday mobilities is implicated in the lived experiences of the informal settlers in a climate change context.

\section{Theoretical framework: Gendered spaces of work and mobilities}

\section{Importance of localities}

It has long been recognised that there tends to be divisions in the travel trends of men and women (Rosenbloom, 1993; Law, 1999). These differences include trip purposes, trip distances, complexity of daily mobility and access to private and public transport (Hanson, 2010; Uteng, 2009. For instance, it has been found that women tend to make shorter and more complex trips due to their multiple roles in society (i.e. carers and workers) and rely on specific modes of transport, such as walking and public transportation (Adeel, Yeh and Zhang, 2017; Sola and Wilhemson, 2012). There is also evidence that women tend to negotiate more at work, as they engage with fixed housework and childcare more frequently (Schwanen, Kwan and Ren, 2008). Such explanatory and descriptive investigations of how women travel have understood transport as hard infrastructure and mobility as a bodily act, 
such as getting to work (Cresswell and Uteng, 2008). Feminist scholarship has mobilised these descriptions to incorporate the concepts of family, work spaces, and household negotiations as central units of analyses, which has resulted in a rich knowledge base for sociology of work and urban studies (Hanson and Pratt, 1994; Law, 1999; Hanson, 2010). The gender, work and family intersection lens has particularly emphasised the role of localities, including neighbourhoods and activity spaces of families, in understanding the geographies of gendered work spaces (Law, 1999; Adler, 2019).

The specific localities in which everyday mobilities are embedded become even more important when considering the economic dimension of the interrelationships between gender and mobility, which manifest themselves in the segregations of local labour markets through the commuting practices, means of access to work, access to infrastructure and work-related mobilities of women (Akyelken, 2017; Cook and Butz, 2017). In this respect, much of the work on gender differences in journey-to-work patterns points to the importance of socioeconomic characteristics and wider political-economy contexts, such as workplaces, cities and regions (McDowell, 2009; Akyelken, 2017). Others have also traced the everyday mobilities of women of different social groups, pointing to the centrality of commuting to revelations of race, gender and class (Levy, 2013; Preston and McLafferty, 2016). These empirical investigations largely conform to the main assumption behind the new mobilities paradigm that "...mobilities need to be examined in their fluid interdependence and not in their separate spheres" (Sheller and Urry, 2006: 212). Combined with the feminist reinterpretation of work that has opened up analysis of diverse sites of work, the social construction of work in terms of gendered spaces has become increasingly interwoven with mobility interdependencies (England and Lawson, 2005).

\section{A relational approach to work-home links}

One of the key interdependencies between gender and mobility concerns the spaces of negotiations in power relationships; e.g. the interventional role of home in the workplace requires women to negotiate at work (Scholten et al., 2012). For example, a male perspective in a UK context has shown that under capitalist production systems, men negotiate at home and benefit from reducing their domestic labour to balance their workload at work (Smith and Winchester, 1998). 'Home and work' and 'public and private spaces' can be considered as the key spaces of negotiations, where women are exposed to multiple daily tasks and social roles. Thinking around these binaries is particularly helpful in investigating the relational understanding of work and space. However, one should note that this framing was originally based on Western trends of urbanisation, where private and public spaces tended to be clearcut (Law, 1999). Women's spatial constriction in non-Western contexts should be carefully studied in terms of the relational nature of their negotiations in everyday life spaces, where the lines between the places of paid and unpaid work are becoming increasingly blurred. Indeed, this was the main implication and consideration of several studies on gender and mobility conducted in non-Western contexts, such as consideration of governance, political conditions and local planning, and the intricate relationships between home and workplace (e.g. Akyelken, 2013, 2017; Cook and Butz, 2017; Levy, 2013). The importance of a 
relational approach also becomes evident in considering mobility and immobility amongst different groups of people, and different forms of mobilities (Bagheri, 2017; Cook and Butz, 2017), which requires questions around how women's ability to move is influenced by the mobility of other household members, and access to transport services.

\section{Multiple meanings of mobility}

Mobilities scholarship have been concerned with the analysis of the meanings women attach to different forms of mobility, and how they are generated by cultural practices, media, government and social policies (Cresswell, Dorow and Roseman, 2016). Political-economy and economic geography approaches have deployed gendered commuting patterns as a way of framing women's economic (dis)empowerment through capitalist production and reproduction (Roseman, Barber and Neis, 2015). Physical movements should be interpreted broadly to include consideration of realms of meanings, aspirations and competence (Cresswell, Dorow and Roseman, 2016; Kaufmann, 2016), particularly given the various difficulties that women living in informal settlements experience. The broader meanings of mobility and work could help map out both predictable commuting patterns and fluid instances of women's work-related (im)mobilities.

According to the conceptual tools provided by the gendered mobilities and feminist readings of work, women's work-related mobilities can be considered a product of power (negotiations), localities, relationalities between everyday urban spaces and temporalities, and meanings given to mobilities. In order to understand these mobility-enabled explanations of work in the face of floods, this study employs an exploratory approach to capture both predictable and fluid patterns at the nexus of gender, flood and work-related mobilities. Specifically, the wider meanings of mobility, localities and everyday life spaces of negotiation and relationalities will become central to the investigation of the work and commuting patterns of women living in flood-prone areas.

\section{Research context and methodology}

Research context

Metro Manila is home to a population of 12.88 million and classified as entirely urban (Philippine Statistics Authority, 2019). It is situated in a floodplain, open to Manila Bay and Laguna de Bay and is vulnerable and exposed to urban flooding. When asked about the last flooding event they remembered, some of the residents were unable to remember the details, although the majority of them said that one of the most destructive tropical cyclones (Ketsana) occurred in 2009. The cyclone caused severe flooding and resulted in many casualties and the displacement of around 435,000 people (Weaver, 2009). In addition to flooding disasters, there are also more frequent floods due to thunderstorms in Manila that causes significant levels of congestion (Lagmay et al., 2017). Indeed, the residents talked about floods more as everyday life risks, and mostly think that floods occur because of inadequate infrastructure (e.g. damaged drainage systems and clogging due to waste). They seem to have a community-developed common local language around floods. For instance, 
they described their coping strategies in terms of the height of the water (i.e. knee-high floods or less than knee-high). They also mentioned being able to walk in water, and not keeping their sensitive appliances on the first floor, as their key coping strategies. Many residents also mentioned the importance of 'thinking ahead' in terms of what to do in the event of a flood (e.g. leaving home for work earlier than usual). Figure 1 shows community-developed warning signs in one of the barangays, in which this study took place.

[Figure 1. Flood warning signs]

Informal settlements are very common in Manila: around one quarter of families depend on informal housing (Singh and Gadgil, 2017). In terms of governance and administration, the metropolitan region consists of 16 cities, and one municipality that is grouped into four major districts. The smallest administrative units are known as the 'Barangays', which act as the primary planning and implementing units of government policies, programmes and activities in the community. However, according to the discussion with local experts, it is possible to say that there is no specific rationale behind how the Barangays are defined and established in practice. According to one of the experts, 'they just be... there is a historical dimension to it.' Another one says, 'as long as they are willing to organise themselves, they are recognised as Barangays.' Based on his personal experience and technical knowledge of the drainage system, one expert even said that drainage needs are addressed 'depending on the aggressiveness of the Barangay leader!' For the residents, the Chairmen of the Barangay are almost like respected family members, who address their needs by providing them with livelihoods (e.g. jobs in the management team of the Barangays), peace and safety in their neighbourhoods (e.g. 'thanks to our Barangay Head, there are no longer any fights here').

The study was conducted in four barangays located in Leveriza in September 2016. The interviewees were recruited by De La Salle University's Centre for Social Concern and Action (CSCA). Leveriza is an actual street in the district of Malate of Manila, but is used by the CSCA to represent the areas included in the fifth legislative district of Manila, which corresponds to the geographical areas of Ermita, Malate, Paco, Intramuros, and San Andres Bukid (De La Salle University, 2016). The four barangays, in which this research took place were located in the district of Malate (Figure 2).

[Figure 2. The district of Malate]

The number of households in the four barangays ranged from 190 to 1,045 (De La Salle University CSCA, 2016), and the populations from 759 to 5,848 (City Population, 2019). The public transport system in Manila is highly motorised and run by private operators. The key transport services include buses, jeepneys (minibuses), tricycles (motorised, threewheeled), and pedicabs (three-wheeled bicycles with a sidecar). The jeepneys, pedicabs and tricycles are the main modes of transport used by the interviewees in the Leveriza Street. Leveriza is also very close to the jeepney pick-up stops. The barangays consist of narrow mixed-use streets, including both residential and commercial spaces. Commercial spaces include small grocery shops that are attached to homes (i.e. sari-sari shops), as pictured in 
Figure 3. There are several types of informal work being done in homes, largely by women, including nail care, hairdressing and cooking.

[Figure 3. Sari-sari shop]

\section{Research design and methods}

Exploratory in nature, this research is designed as a qualitative study. Before starting the fieldwork, I worked with a local academic team on a review of policy documents on transport and climate change governance in Metro Manila, following a two-day workshop that took place in the UK in November 2015. I also visited the four barangays and conducted four expert interviews before we started interviewing the residents. The expert interviews were conducted with two engineers, an urban planner and a social advocate who had had extensive experience working with informal settlements in Manila. These interviews aimed at understanding how the informal settlements were perceived in policy, as well as confirming the initial themes that emerged from the document review. This was particularly helpful in identifying the localities.

The fieldwork consisted of conducting 21 in-depth resident interviews and a woman-only focus group discussion. The interviewees included a group of working men (8) and women (13), who were recruited by the De La Salle University CSCA according to the criteria for inclusion I provided: I focused on working men and women of a variety of ages and educational backgrounds and marital status. More than half of the women I interviewed were married with children and lived with their extended families. To illustrate the living conditions of the sample: it was very common for a married working woman to live in a three- or four-floor house, where she occupied one or more of the rooms with her spouse and children. Some also mentioned that living in upper floors was almost an 'upgrade' in living, due to the reduced risk of flooding.

The purpose of the one-to-one interviewing was to gain a deeper understanding of the lived experiences of men and women in terms of their everyday life mobilities, especially in travelling to work during floods, as well as their long-term plans and aspirations. The interview commenced with broad questions, such as 'What do you do for living?' 'What is your occupation?' It then continued with more probing questions designed to explain the main drivers behind their job selection and their educational backgrounds. The second part of the interview was about how they got to work and how they travelled within Manila. These questions varied depending on individual circumstances, as the residents' commuting patterns and occupations were diverse; e.g. from postman to engineer for men, and from teacher to home-working house sales representative for women. I also asked questions about their physical surroundings and how they perceived the changes to their neighbourhoods, and their perception of accessibility and mobility in Manila. Finally, the floods were discussed in relation to their mobility within the city. In many of the interviews, the interviewees had already mentioned floods as one of the challenges in getting to work, so the 
order of the questions changed in some. Each interview took 35-50 minutes on average. The interviews and the focus group were recorded and transcribed.

Focus group discussion consisted of eight women from a wide range of age groups (four aged above 55, and four aged below 35), including single and married women of different occupational backgrounds. The other criteria for inclusion included some of them having experienced floods in the form of a disaster. This was to see if experiencing floods in the form of a disaster changed their perceptions of everyday flood risks. The main rationale behind the use of a woman-only focus group was to understand women's perception of climate change and floods, and what they know about the mobility options available to them. The interactions within the focus group discussion revealed the level of knowledge that the women residents had on their surroundings and the opportunities and challenges they face. Such investigation into the environmental knowledge base of the women residents was useful in shedding light on the social production of the local environments (Swyngedouw and Heynen, 2004), for which gendered knowledge in sustaining ecologically viable livelihoods is an integral element.

The main practical limitation of the study was the language barrier. While most of the interviewees spoke English, some were not very comfortable expressing their feelings in English and had to change to their local language for some parts of the interviews. A translator was therefore needed, which slightly disrupted the tone of the discussion. Different interpretations of English words were also noted: for instance, what the interviewees mainly understood from the word 'travel' was 'a holiday trip'. It was therefore misleading to ask questions, such as 'How do you travel within the city/travel to work?' Having noted this at the beginning of the fieldwork, I changed the way I asked questions in the subsequent interviews, in liaison with the local team.

Perhaps a more profound limitation concerned my position in the eyes of the participants: I was coming from a UK institution that almost all of the participants had heard about. Combined with my lack of deep engagement with the local context, the study can be considered extractive and may raise questions about power inequalities in research relations. Together with my colleagues, I was introduced to the participants through the local collaborator and the CSCA, which the participants were already familiar with. This created some level of trust, but it was evident from the discussion with some of the participants that they felt shy in expressing their views. I therefore kept the questions as specific as possible and came up with more probing questions to leave space for them to elaborate as freely as possible. I have also paid particular attention to how local knowledge and residents' experiences could be implicated in urban development strategies in climate change contexts as recognised by the international development agenda. I have taken a critical perspective to the global relevance of the frameworks that have emerged in the Global North, by paying particular attention to precarity and the undefined boundaries of everyday urban spaces in Global South contexts (Porter, 2016). It could therefore be argued that the implications of the actual lived experiences of the participants will contribute to the development agenda by critiquing universally accepted, one-size-fits-all development solutions. 
In interpreting the data, I have mobilised the theoretical framework to classify the themes from the interviews and problematise rigid definitions of women's work spaces and mobility interpretations (i.e. paid/unpaid work; home-work; negotiating actors, etc.). The analysis first focused on the key themes emerged from the residents' commuting patterns. It continued with an iterative process, whereby different patterns of access to work and perceptions of accessibility were analysed using 'mobility' as the unit of analysis and what broader meanings it entailed from the perspective of the residents. The explication of the data through these mobility dimensions brings a novel perspective to the analysis of lived experiences of a flood in terms of access to economic opportunities in informal settlements. It sheds light on everyday mobilities, but also on spaces of negotiation in relation to getting to work. It also shows the relative importance of physical distance, risk of flooding and other challenges at work and at home in women's everyday lives and their future aspirations.

\section{Gendered work-related (im)mobilities in a climate change context}

\section{Governance-related, physical, economic and social localities}

In human-geographical literature, 'locality' tends to be defined in terms of epistemologies: for instance, the Marxist view sees it as a place-specific social phenomenon created by uneven capitalist development, whilst according to post-structuralists, localities are open, plural and dynamic (Clarke, 2013). The commonalities between different definitions of a locality are that they are of a sub-national scale, different from place and mostly humanmade; they do not have well-defined boundaries. I use the term to denote the range of experiences and contextual characteristics bounded by the everyday activities of people in a given place. The interviews with local experts and residents depict the local physical, economic, climate-governance and social attributes of the local community that define these localities, in which work-related mobilities are embedded. There are notable interdependencies between physical attributes (i.e. built environment and physical accessibility) and economic resources (i.e. availability of jobs), and between social attitudes and climate-governance attributes.

Looking at the nexus of climate governance and the perceived social attributes of the local communities (i.e. informal settlements in Metro Manila), one can observe some degree of acceptance — and almost normalisation — of the adverse implications of the climatic conditions and the lack of capacity in local governments. All experts referred to the 'capacitating the communities' approach when asked to describe climate change governance in relation to the informal settlements in Manila. Although there are issues around access to resources, the capacitating the local communities approach (i.e. teaching and training the communities to identify risk/hazards and take precautions) has been widely mobilised by local actors in in Metro Manila for the informal settlements (Tadgell, Mortsch and Doberstein, 2017). The urban planner defined it as a tool to engage a diverse range of stakeholders, including informal settlements, churches, and the national housing associations for urban matters, which entails largely soft policies, such as providing information on weather-related events and giving preventative advice (e.g. keeping canned foods at home at 
all times). The engineers also mobilised participatory and community mapping, which is heavily dependent on the data and information provided by these communities, in identifying the risk of a hazard on the electricity system. According to them, the need for this bottom-up approach emerges from the lack of adequate capacity in the local governments and difficulties with access to the communities.

At a more general level, the key driver behind the capacitating the communities approach seems to be trust in the strong social networks within these communities. 'These urban communities are well organised. They have sympathy for each other', says the social advocate showing full trust in these communities. The experiences of the women during the Katsana Typhoon (e.g. helping each other with transferring food and cleaning each other's homes) confirm the benefits of these networks. The fact that borrowing money within the same Barangay is a common practice also reveals the existence of close networks to some extent. In addition to this reliance on local social networks, perceptions also extend to women's spaces of work in informal settlements that would be exposed to climatic risks: two of the experts mentioned that because women in such communities tend to work at home, floods damage these women's appliances or goods which may affect their 'home-based sales activities' but not their access to work.

However, looking at the nexus of economic and physical localities, such societal descriptions of the localities do not necessarily conform to the lived experiences and aspirations of the working women. Whilst there is a clear consensus amongst the residents that Leveriza is a popular living and working space, due to its central location, unpacking the details shows the role of physical access to be redundant when considering family lives and individual aspirations. All residents mention the fact that Leveriza is getting overcrowded and all share the view that more people are coming to Leveriza, because '[they are] at the centre of everything', emphasising its accessibility for job opportunities and public transport. Born and raised in Leveriza, a woman in her 40s describes the changes to the neighbourhood: 'there are more objects, more sari-sari stores ... because there are more people want to have additional income.' Some also point to the Leveriza being used as a 'bed place' for migrants: '... Many workers in Manila are boarding in Leveriza - the Barangay provides accommodation.'

The latter view — that more space being made available for 'incomers' — entails negative connotations to the point that some of women residents, especially those with young children, want to leave Leveriza, as they feel that their local community is being ruined by strangers: 'I don't want to live here, because my children are young and the surroundings are not good... I don't like this environment for my children.' This married teacher with three sons currently lives together with her parents and is eager to move to her new house that may be even more flood-prone and is far from the school at which she works and her children study: '... [we] will commute longer distances. Because we want to have our own place. For us to own our own place, for us to be independent.' When asked what she means by independence, she says 'So we may not ask our parents for money... If we don't have the money, we borrow from my mama. We want to stand on our own feet.' The woman is willing to commute longer and 
live with a higher threat of flood to achieve independence for her family. As illustrated by this example, preferring independence and empowering their families may determine their willingness to move. In this respect, some of women domestic migrants' perceptions of Leveriza are also notable; a young woman, for instance, had migrated from the countryside and ended up taking a job as a mobile worker (e.g. housing sales representatives) but was eager to move to other parts of the city. The economic independence she gained in Leveriza through their mobile jobs enabled her to be more mobile in terms of residential mobility.

The relative importance of physical access to jobs and the urge for economic independence amongst the women residents (and their efforts in protecting and empowering their families) reveal stark contradictions when contrasted with the image of women's work being usually homebound, and the community close-knit and strongly bonded. The meanings given to work and mobility also had an international dimension, which extended women's aspirations beyond the localities. The focus group discussion yielded some interesting insights into the international mobility of the women. Some women had worked in the past as transnational workers in fields ranging from singing to care work. The narratives around the women's aspirations were varied. For instance, having watched a Western film portraying the life of service workers on luxurious cruises, one woman mentioned that she wanted to work on a cruise ship abroad. Overall, the combined analysis of different forms of localities reflects the spatially confined understanding of women's work spaces and the augmented power of the social networks within these communities, where the individual aspirations and symbolic meanings given to mobility are underestimated.

\section{Work-home negotiations and mobility-induced relationalities}

The interviews with the residents reveal that there are both temporal and spatial relationalities that emerge from home-work negotiations in flood-prone contexts. The most evident role of floods appears in the temporal relationality between the residents' commuting patterns and their home lives. The commuting experiences of the interviewees seem to share issues with those of any citizen in the city. Congestion is the main nuisance caused by floods, which significantly affects their access to workplaces. Floods seem to exacerbate existing everyday life challenges for residents of all genders working regular hours. The challenges worsened by floods go beyond their constant need 'to adjust their time', whereby they factor in the increased commute times that characterise the increasingly dense city of Manila. With floods, these challenges are exacerbated to the extent that they affect their basic survival needs, such as being able to eat regularly and having enough sleep. 'I am not able to eat on time!' was simply the first reaction of a young man working as a repairman, within 30-45 minutes jeepney ride from his home, when asked about how floods affect his life in general.

A gender dimension appears in the implications of commuting times for the types of jobs that women and men can take, which points to another temporal relationality, this time between everyday life constraints and life course choices. It is possible to argue that men can take jobs that require long commutes or multiple trips a day, such as delivering post for the local church. A young man working as a messenger for the Council particularly emphasises the 
number of unpredictable trips that he has to make in a typical day. This seems to be the case regardless of the weather conditions; however, one woman interviewee added that men do not go back to their homes during a flood. In fact, many tricycle drivers (a very common occupation for men living in the informal settlements) usually finish late in the evening, and in the case of flooding they sleep in their tricycles wherever they are. Amongst the educated (i.e. with university degrees), men can take high-skilled jobs (e.g. engineers) and work in distant offices/sites. In an interview with an engineer, it was revealed that some men working distant offices do not even go back home during the week. The situation changes for women: a young woman pointed to the commuting distance as her main reason for leaving "her dream job" with a clothing retailer in a shopping mall in Makati City. She complained about congestion, which wasted significant degree of her time on the roads. Currently working in her parents' shop, located on the first floor of her house, she finds it is easier to work at home. Home-based economic activities are indeed common across all age groups, and even amongst the well-educated, but many holding full-time jobs do additional work in family shops, especially at night, so homebound activities may become part of the women's work package as well.

Regardless of gender, and no matter how well these communities are equipped to cope with flooding in everyday life, the final decision on whether they get paid if absent from work, or delayed, or in the case that their workplace gets shut during the flood, lies with the employer. In several cases, women mentioned the issue of no pay in such events, and, in one instance, getting double paid if they are able to make it to the work during the floods (literally by walking through knee-deep water). The harsh negotiations in the workplaces on issues of lateness and extra hours (e.g. a 'no work no pay!' policy) affect both men and women. A young man working at a call centre to save money for his wedding says that he is particularly careful to get on the jeepney much earlier than usual if there are flood warnings, as 'for every minute you are late, you have to work for extra hour'. Some of these everyday life (temporal) constraints, emerging from the power inequities between employers and employees, as observed in the negotiations relating to life course events (e.g. marriage), do not seem to have a gender dimension.

Another gender difference can be observed in the perceived convenience of public and private forms of transport and infrastructure. Unlike men, women do not paint a positive picture of the transport accessibility of Leveriza Street. The timings of the jeepneys and the high share of public transport costs in their family budgets are frequently mentioned when discussing their views on transport services. Private transport (e.g. having one's own motorbike, car or tricycle) is preferred over public transport for affordability reasons. The majority of women mentioned that they either had bought, were planning to buy, or would like to buy a motorbike through a bank loan. Some even mentioned that modifications (e.g. elevating the seat) were needed to their motorbikes to cope with floods when going to work. In terms of infrastructure, flooding of the walking paths particularly affected the women who worked nearby in low-paid jobs (e.g. in hotels or shopping centres or in houses as cleaners on a casual basis). For instance, teachers' journeys to work were not necessarily affected by floods, as schools were normally shut during heavy floods. Amongst the low skilled, there 
were women, who had no choice as to whether to go to work or not depending on the weather conditions, unless their workplaces were shut. One of them said, 'I will go to work whatever the weather is... I don't care about the flood, because I have to go to work.'

Combined with the multifaceted nature of daily activities and commute times, the perceived inconvenience of the transport services also tended to change the gendered division of labour in the household. It was mentioned in at least two different cases, that the male head of the household had become a tricycle driver in order to take their wives to work and children to school: 'He takes me to work in the morning, and then goes home and picks me up at $12 \mathrm{pm}$. In the afternoon, he goes to Harrison Plaza as a driver until late night.' She found it difficult to take the jeepney to work because of the inconvenient times. She particularly mentioned that he looked after the children in the morning until she got back from work. While the male head being a tricycle driver points to a certain way of living in households, it can also be argued that the negotiations within the household usually revolve around getting access to work.

\section{Discussion: conflicting logics of confinement and independence}

Coastal cities are increasingly vulnerable to flooding. The urban poor are at an even higher risk due to their settling in low areas exposed to flooding. Combined with rapid urbanisation, increasing urban densities and the rising threat of climate change, a thorough understanding of the needs of vulnerable social groups is more important than ever. The academic and policy framings of urbanisation in a development context has singled out women living in low-income areas exposed to flooding as the main victims (Sultana, 2010; Chant and Mcllwaine, 2016). With this paper, I have shown the value of the gendered mobilities lens in unpacking the complex dynamics of low-income communities' everyday working lives in flood-prone urban contexts in the Global South. Specifically, I have sought to understand how the daily mobility of low-income communities, particularly that of women, is related to the broader social, economic and environmental contexts of work, workplaces and working lives in flood-prone urban contexts. I have drawn on gender, work and mobilities scholarship to explore the broader meanings women attach to mobilities and to analyse everyday life mobility in terms of spaces of negotiation, relationalities and localities. Rather than looking at floods as disasters, I have considered floods as an everyday life risk for the residents of informal settlements. In doing so, the interactions between different spaces of negotiation and their implications for the (im)mobility of women in the face of everyday risk of flooding have also been elucidated.

There are four groups of findings that corroborate the existing evidence on the role of gender and socioeconomic background on perceived transport accessibility, daily time-related constraints and occupational segregation. First, in accessing work, floods seem to affect the time spent on commuting by both working men and women due to increased congestion. Congestion is a key challenge that affects working men and women and creates further burdens and concerns amongst the low-income communities. Second, with regards to gender, commuting time that varies with floods (and flood risks) tends to determine the 
types of jobs taken up by men and women in some cases. Third, women have a more negative perception of transport accessibility and convenience and have developed more flood-specific coping strategies (e.g. modifying their motorbikes to make them more floodresilient). Finally, inadequate transport services and infrastructure seem to be a more critical issue for less skilled women holding informal jobs, as they have to go to work regardless of the weather conditions. The determining role of commuting distance and the transport disadvantages experienced by low-skilled women living in flood-prone contexts show similarities to the gendered constraints on transport and mobility in other contexts (Uteng, 2009; Akyelken, 2017).

I have provided a feminist reading of everyday mobilities and urban floods through analysis of commonalities and differences in mobility-related difficulties that women and men experience. This perspective extends the understanding of the relationship between climatic events and everyday mobilities, with two broader conclusions.

First, the juxtaposition of the climate-governance, physical, social and economic localities show that flood-related difficulties are identified according to the presumed immobile nature of women's work (i.e. that they adversely impact their work by damaging their goods, but not their access to work). However, delving deeper into floods as lived and experienced; women's urgency for economic independence reveals that such an understanding of women's work spaces is spatially confined and that the power of social networks in these communities is overestimated. Moreover, the interplay of women's care for family with work-related mobilities is not necessarily due to the emotional and caring nature of being a woman, as is often assumed (McDowell, 2009). They rather aspire to empower their families: they feel that they do not have enough control over raising their children and would like to move out of Leveriza to achieve economic independence for their families, despite longer commute distances and greater threat of flooding.

Second, the analysis of the relational nature of everyday negotiations point to the role of mobility needs, socioeconomic backgrounds (skilled versus unskilled workers) and the increasingly crucial role of the emerging actors, such as employers, in the social construction of women's working lives in flood-prone contexts. Together, they show that, as important as household negotiations may be to the residents' economic vulnerability in the face of floods, there are other actors, such as employers and the policy-makers that affect informal settlers' daily temporal and spatial constraints. Moreover, the binaries regarding public-private and home-work links are getting blurred, due to negotiations concerning mobility and daily time constraints, which then change the division of labour at home. The spatial and temporal relationalities between work, mobility and home over time entangles widely assumed gendered division of labour in households and in cities.

The central conceptual narrative emerging from the analysis is the conflicting logics of confinement and independence mediated by mobility. The efforts to empower women informal settlers through capacity-building activities (e.g. by providing environmental knowledge) presume that they are mostly homebound, which is in line with the assumptions 
behind the instrumental role given to women in development contexts. This spatially confined understanding of women's work spaces is noticeably challenged by further investigation into the meanings given to mobility in relation to work by both married and single women. Such investigation exposes women's urge for economic independence and empowerment, which goes beyond the widely assumed belief in women's bodily and emotional non-productive labour. Overall, the societal descriptions of women's work spaces do not necessarily conform to lived experiences.

Unlike the challenges imposed by negotiations in the household that have occurred in North American and Western European contexts (Schwanen, Kwan and Ren, 2014), in Malate, negotiations revolve around employment and flood-induced mobility difficulties in the household. The household, where transport-related challenges change the division of labour, almost becomes a source of independence, which contradicts the view that gendered family roles are spatially constraining for women (Akyelken, 2017). The aspirations of the lowincome communities - especially those of women - also go well beyond national borders, as exemplified by their long-term ambitions. Such thinking around mobility and independence coincides with claims that point to the misleading implications of associating mobility with power (Hanson, 2010). This also confirms the need for conceptualising employment-related geographical mobility as a spectrum in the informal settlements, in order to gain a deeper understanding of mobility-related challenges and aspirations (Cresswell et al., 2016).

In conclusion, a focus on the working lives of women informal settlers, as they negotiate in multiple spaces emerging from flood-related difficulties, enhances the social construction of work and mobility for women living in a Global South context. The multiplicity and richness of the complexity of women's everyday lives in adverse environmental and economic conditions enhance the explanatory power of the gendered mobilities perspective. The theoretical frameworks constructed in capitalist systems in the Global North have been critiqued primarily due to their irrelevance to precarious livelihoods (Schwanen, 2018). Given that this paper particularly critiques the notion of spaces of work by incorporating the environmental and physical local conditions and relaxing rigid boundaries, such as workhome links or binary relationalities, the context-specific attributes add to the meaning of work and mobility for precarious lifestyles as well as for those holding regular jobs. In doing so, we also refrain from homogenising the urban South by avoiding the generalisation that informal settlers hold informal jobs and they are locally constricted, as can appear in the policy agenda. Finally, the discussion has shown that the policy should consider the fact that flooding may be a regular occurrence (rather than a natural disaster only) that requires negotiation in multiple spaces of everyday life, particularly for the low-income communities. Hence, policies should also reflect that the emphasis on the social networks of close-knit communities may lead to generalisations that the powered relationships between different actors may be understated.

\section{References}

Adeel, Muhammad, Yeh, Anthony.G.O. and Zhang, Feng. (2017) 'Gender inequality in 
mobility and mode choice in Pakistan', Transportation, 44, pp. 1519.

Adler, Marina (2019) Space and the intersection of gender, work and family. In: (Eds) Halatcheva-Trapp, Maya, Montanari, Giulia. and Schlinzig, Tino Family and space: rethinking family theory and empirical approaches. Abingdon: Routledge. Chapter 5.

Ajibade, Idowu, McBean, Gordon and Bezner-Kerr, Rachel (2013) 'Urban flooding in Lagos, Nigeria: Patterns of vulnerability and resilience among women', Global Environmental Change. 23(6), pp. 1714-1725.

Akerkar, Supriya, Joshi, P. C. and Fordham, Maureen (2016) 'Cultures of Entitlement and Social Protection: Evidence from Flood Prone Bahraich, Uttar Pradesh, India', World Development, 86, pp. 46-58.

Akyelken, Nihan (2013) 'Development and Gendered Mobilities: Narratives from the Women of Mardin, Turkey’, Mobilities, 8(3), pp. 424-439.

Akyelken, Nihan (2017) 'Mobility-Related Economic Exclusion: Accessibility and Commuting Patterns in Industrial Zones in Turkey', Social Inclusion, 5(4), pp. 175-182.

Azad, Abul Kalam, Hossain, Khondoker Mokaddem and Nasreen, Mahbuba (2013) 'Floodinduced vulnerabilities and problems encountered by women in northern Bangladesh', International Journal of Disaster Risk Science, 4(4), pp. 190-199.

Bagheri, Nazgol (2017) 'Tehran's subway: gender, mobility, and the adaptation of the “proper" Muslim woman', Social \& Cultural Geography. Routledge, 9365(October), pp. 119.

Bob, Urmilla and Babugura, Agnes (2014) 'Contextualising and conceptualising gender and climate change in Africa’, Agenda, 28(3), pp. 3-15.

Chant, Sylvia (2013) "Cities through a "gender lens": A golden "urban age" for women in the global South?', Environment and Urbanization, pp. 9-29.

Chant, Sylvia and Mcllwaine, Cathy (2016) Cities, slums and gender in the global south: towards a feminised urban future. London: Routledge.

City Population (2019). Phillippines Metro Manila. https://www.citypopulation.de/Philippines.html

Clarke, Nick (2013) 'Locality and localism: A view from British Human Geography', Policy Studies, 34(5-6), pp. 492-507.

Cook, Nancy and Butz, David (2017) 'Gendered mobilities in the making: moving from a pedestrian to vehicular mobility landscape in Shimshal, Pakistan', Social \& Cultural Geography, pp. 1-20.

Cresswell, Tim, Dorow, Sara and Roseman, Sharon (2016) 'Putting mobility theory to work: Conceptualizing employment-related geographical mobility', Environment and Planning A, 48(9), pp. 1787-1803. 
Cresswell, Tim and Uteng, Tanu Priya (2008) Gendered Mobilities. Abingdon: Routledge.

De La Salle University Centre for Social Concern and Action (2016). Personal

Communication. September 2016.

Eastin, Joshua (2018) 'Climate change and gender equality in developing states', World Development, 107, pp. 289-305.

England, Kim and Lawson, Victoria (2005) Feminist Analyses of Work: Rethinking the Boundaries, Gendering, and Spatiality of Work. In: Nelson, Lise and Seager, Joni (Eds.) A Companion to Feminist Geography. Oxford: Blackwell. Chapter 6

Hanson, Susan (2010) 'Gender and mobility: New approaches for informing sustainability', Gender, Place \& Culture, 17(1), pp. 5-23.

Hanson, Susan and Pratt, Gill (1995) Gender, Work and Space. London: Routledge.

Kaufmann, Vincent (2016) 'Mobility, motility: What determines our ability to move ?', Forum Vies Mobiles, pp. 7-9.

Ingham, Valerie, Islam, Mir Rabiul and Hicks, John (2019) 'Adaptive flood mobilities in Bangladesh', Mobilities, 14(2), pp. 158-172.

Lagmay, Alfredo Mahar et al. (2017) 'Street floods in Metro Manila and possible solutions', Journal of Environmental Sciences, 59(September), pp. 39-47.

Law, Robin (1999) 'Beyond "women and transport": Towards new geographies of gender and daily mobility’, Progress in Human Geography, 23(4), pp. 567-588.

Levy, Caren (2013) 'Travel choice reframed: "deep distribution" and gender in urban transport', Environment and Urbanization, 25(1), pp. 47-63.

Mason, Lisa Reyes and Agan, T. Celeste (2015) 'Weather variability in urban Philippines: a gender analysis of household impacts', Climatic Change, 132(4), pp. 589-599.

McDowell, Linda (2009) Working Bodies: Interactive Service Employment and Workplace Identities. London: Wiley-Blackwell.

McDowell, Linda (2016) 'Reflections on feminist economic geography: Talking to ourselves?', Environment and Planning A, 48(10), pp. 2093-2099.

Perez, C. et al. (2015) 'How resilient are farming households and communities to a changing climate in Africa? A gender-based perspective', Global Environmental Change, 34, pp. 95107.

Philippine Statistics Authority (2019). Highlights of the Philippine Population 2015 Census of Population. Available online at: http://www.psa.gov.ph/content/highlights-philippinepopulation-2015-census-population 
Porter, Gina (2016) 'Mobilities in rural Africa: New connections, new challenges', Annals of the American Association of Geographers, 106(2), pp. 434-441

Preston, Valerie and McLafferty, Sara (2016) 'Revisiting gender, race, and commuting in New York', Annals of the American Association of Geographers, 106(2), pp. 300-310.

Roseman, Sharon R., Barber, Pauline G. and Neis, Barbara (2015) 'Towards a feminist political economy framework for analyzing employment-related geographical mobility’, Studies in Political Economy, 95, pp. 175-203.

Rosenbloom, Sandra (1993) 'Women's travel patterns at various stages of their lives', In: (Eds.) Katz, C. and J. Monce Full Circles - Geographies of Women. London: Routledge. Chapter 11.

Rufat, Samuel et al. (2015) 'Social vulnerability to floods: Review of case studies and implications for measurement', International Journal of Disaster Risk Reduction, 14, pp. 470-486.

Scholten, Christina, Friberg, Tora and Sanden, Antika (2012) 'Re-Reading time-geography from a gender perspective: Examples from gendered mobility', Tijdschrift voor Economische en Sociale Geografie, 103(5), pp. 584-600.

Schwanen, Tim, Kwan, Mei-Po and Ren, Fang. (2008) 'How fixed is fixed? Gendered rigidity of space-time constraints and geographies of everyday activities', Geoforum, 39(6), pp. 2109-2121.

Schwanen, Tim (2018) 'Geographies of transport III: New spatialities of knowledge production?’, Progress in Human Geography, 42(3), pp. 463-472.

Sheller, Mimmi and Urry, John (2006) 'The new mobilities paradigm', Environment and Planning A, 38(2), pp. 207-226.

Singh, Gayatri and Gadgil, Gauri (2017) Navigating Informality Perils and Prospects in Metro Manila’s Slums. Washington DC: The World Bank Group.

Smith, Glendon D. and Winhester, Hilary P M. (1998) 'Negotiating space: alternative masculinities at the work/home boundary', Australian Geographer, 29(3), pp. 327-339.

Solá, Gil Ana and Vilhelmson, Bertil (2012) 'Convergence or divergence? Changing gender differences in commuting in two Swedish urban regions', Cybergeo: European Journal of Geography, Article 591.

Sultana, Farhana (2010) 'Living in hazardous waterscapes: Gendered vulnerabilities and experiences of floods and disasters', Environmental Hazards, 9(1), pp. 43-53.

Swyngedouw, Erik and Heynen, Nikolas C. (2004) 'Urban political ecology, justice and the politics of scale', Antipode, 35(5), pp. 898-918. 
Tadgell, Anne, Mortsch, Linda and Doberstein, Brent (2017) 'Assessing the feasibility of resettlement as a climate change adaptation strategy for informal settlements in Metro Manila, Philippines', International Journal of Disaster Risk Reduction, 22(June), pp. 447-457

Uteng, Tanu Priya (2009) ' Gender, Ethnicity, and Constrained Mobility: Insights into the Resultant Social Exclusion', Environment and Planning A: Economy and Space, 41(5), pp. 1055-1071.

Uteng, Tanu Priya (2011) Gender and Mobility in the Developing World, World Development Report Gender Equality and Development Background Paper. Washington, DC. Available at: http://siteresources.worldbank.org/INTWDR2012/Resources/77781051299699968583/7786210-1322671773271/uteng.pdf.

Weaver, Matthew (2009) 'Philippines storm death toll rises', The Guardian. Retrieved from https://www.theguardian.com/world/2009/sep/28/philippines-storm-death-toll 